\title{
Temporal comparison theory and elderly satisfaction with their body: \\ a preliminary study
}

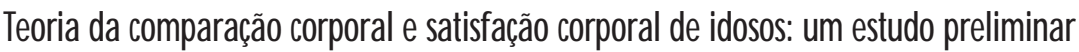

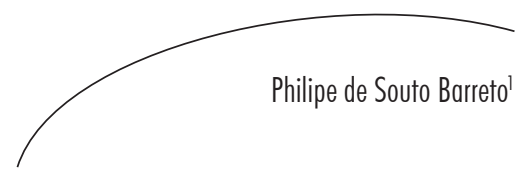

\section{Abstract}

Objectives: Studies on body satisfaction have been neglecting a possible contribution of temporal comparisons (TC) for determining people's satisfaction with their body. The purpose of this work is to provide preliminary data on the usefulness of TC theory in determining body satisfaction in elderly individuals. Methods: Participants were 18 functionally limited elderly adults, aged 68-90 years. After receiving three theory-related stimuli (social comparison, temporal comparison, and self-schema), they completed two scales: a scale on satisfaction with body functioning and a scale on body appearance satisfaction. Results: Satisfaction with body functioning and satisfaction with body appearance did not differ among theory-related stimuli. TCrelated correlations were stronger than the other theory-related correlations, even when adjusted for confounding variables. Conclusions: Our results suggest that TC theory may be a useful framework for explaining body satisfaction in the elderly. Studies on this subject should be encouraged. However, further research is needed before any conclusion can be drawn.

\section{Resumo}

Objetivos: Estudos sobre a satisfação corporal têm negligenciado uma possível contribuição da teoria de comparação temporal a fim de determinar a percepção que os idosos têm do próprio corpo. O objetivo deste trabalho é estudar a utilidade da teoria de comparação temporal na determinação da satisfação corporal de idosos. Métodos: Dezoito idosos, com idade entre 68 e 90 anos, e possuindo certo grau de limitação física, participaram do estudo. Depois de receberem estímulos relacionados a três teorias (comparação social, comparação temporal e self-schema), os participantes completaram uma escala de satisfação com a função física e uma escala de satisfação com a aparência. Resultados: A satisfação corporal não diferiu entre os estímulos relacionados às três

Key words: Body image. Body appearance. Temporal comparison theory. Body functioning. Elderly.
Palavras-chave: Imagem corporal. Aparência. Comparação temporal. Função física. Idoso.

Faculté de Médecine - Secteur Nord, Université de la Méditerranée. Marseille, France. 
teorias aplicadas. Correlações relacionadas à teoria de comparação temporal foram superiores às correlações relacionadas às outras teorias, mesmo quando as correlações foram ajustadas por certas variáveis de confusão. Conclusões: Estes resultados sugerem que a teoria CT parece ser útil para explicar a satisfação corporal de idosos. Estudos sobre este assunto devem ser encorajados a fim que se possam desenhar conclusões sobre bases sólidas.

\section{INTRODUCTION}

Body satisfaction is a very complex and important construct of a person's life. ${ }^{1}$ To understand persons' perceptions of their body, several aspects must be taken into account, such as socio-demographic characteristics (e.g., age, gender), body morphology aspects (e.g., body mass index $[\mathrm{BMI}]$, body fat), behavioral-related aspects (e.g., exercise, nutrition), health-related aspects (e.g., physical function declines, chronic diseases), and socio-cultural norms and ideals.

Theory-based studies have been developed in the field of body satisfaction. Most of them used social comparison (SC) theory to explain persons' satisfaction with their body. This theory hypothesizes that "there exists, in the human organism, a drive to evaluate his opinions and his abilities" ${ }^{2}$ by comparing themselves with others. SC theory has been used in body image studies, ${ }^{3}$ and therefore it is considered a useful framework for understanding how individuals evaluate their body. ${ }^{4-7}$ Another theoretical framework commonly used in body satisfaction studies is the self-schema (SS) theory. Selfschemas are "cognitive generalizations about the self, derived from past experience that organize and guide the processing of selfrelated information". ${ }^{8}$ In this way, when applied to the field of body image, SS theory implies that body image is a mental representation of self-related information.? However, studies have presented mixed results with regard to the usefulness of SS theory in explaining body image. ${ }^{10}$ Temporal comparison (TC) theory has been used in studies on psychological well-being, including among older adults. ${ }^{11} \mathrm{TC}$ hypothesizes that people evaluate themselves by using intrapersonal aspects of the self over time. ${ }^{12}$ For example, in a study using TC theory, Ryff ${ }^{11}$ showed that elderly' past assessments with regard to psychological well-being were generally close to their present assessments, suggesting perceived similarity or maintenance of prior levels of functioning. Even though researchers ${ }^{13}$ have shown the importance of TC among adults of all ages, as far as we know, TC theory has never been applied to body satisfaction studies. Besides, by far the majority of studies on body image have used adolescent and young adult samples to the detriment of older adult populations. ${ }^{14}$ Although declines on physical function, a health condition strongly associated with age, ${ }^{15}$ can influence body image, the relationship between them is still poorly understood. ${ }^{16}$ Therefore little information is available regarding elderly' perceptions of their body; besides, functionally limited older persons have been particularly neglected in studies on body satisfaction. The present preliminary study aims at examining whether TC theory can be a useful framework in the field of body satisfaction in a sample composed of functionally limited French elderly.

\section{METHODS}

To evaluate body satisfaction, this construct was separated into two dimensions: body functioning and body appearance. As indicated by Reboussin et al., "satisfaction with one's body has two components, satisfaction with body function and satisfaction with body appearance"; moreover, these two dimensions present different correlates ${ }^{17}$ and predictors. ${ }^{18}$ Thus, separate assessments and analyses of body functioning and appearance allow a better approach to body satisfaction in the elderly. 
Study Population

We interviewed 18 community-dwelling older men ( $\mathrm{n}=7)$ and women $(\mathrm{n}=11)$, age 68-90 years-old $($ median $=81.5$ years), from Marseille, France. Inclusion criteria were to be $\geq 60$ yearsold and functionally limited. Exclusion criteria were to have a disease that disturbs motor skills (e.g., advanced Parkinson's disease) or cognitive function (e.g., advanced Alzheimer's disease) in an advanced stage.

All participants signed an informed consent form which explained the study objectives and procedures. This study complies with ethical standards in France.

\section{Measures}

Satisfaction with body functioning. This was assessed by a 5-item (e.g., "In the past four weeks, how satisfied have you been with your overall muscle strength?") body functioning scale $\left(\mathrm{BFS}^{18}\right)$. BFS scores can vary from 5 to 25 , with higher scores indicating higher levels of satisfaction.

Satisfaction with body appearance. This was assessed by a 3-item (e.g., "In the past four weeks, how satisfied have you been with your overall physical appearance?") body appearance scale $\left(\mathrm{BAS}^{18}\right)$. BAS scores vary from 3 to 15 , with higher scores indicating higher levels of satisfaction.

Physical function decline. This was assessed using a 8-item scale (e.g., walking 500 meters without stopping). Scores vary from 0 to 24 for this scale, with higher scores indicating higher levels of physical function decline. ${ }^{19}$ Individuals who indicated they needed help to carry out $\geq 1$ activity of this scale were considered functionally limited.

Disability. This was evaluated by a scale that measures difficulty in carrying out six activities of daily living (ADL. e.g., bathing, dressing). Scores for the ADL scale vary from zero to 18 , with higher scores indicating higher difficulty in carrying out ADLs.
Other variables. Demographic variables (age, gender, and level of education), health-related variables (self-reported osteo-articulatory chronic pain, number of diseases, self-reported health), and anthropometric variables (selfreported weight and height, and then BMI) were also reported. Number of diseases was obtained by adding the following diseases: osteoarthritis, osteoporosis, bronchitis /asthma / chronic emphysema, diabetes, hypertension, cardiac diseases, stroke, Parkinson's disease, cataract, and cancer. BMI was calculated using weight, in kilograms, divided by squared height, in meters.

\section{Study Procedures}

Semi-structured interviews. Participants were individually interviewed at their home. Interviews approached their daily activities and general health. They responded to the BFS three consecutive times and the BAS four times; interval between answers was in average 15 minutes. To reduce the probability that participants memorize their answers, they were not previously informed about specific questions on body satisfaction.

$B A S$ and BFS baseline measures. In the beginning of interviews, participants answered for the first time the BFS and BAS. Then, the interviewer started conversation on participants' daily activities in a typical day.

Body satisfaction and SC theory (BAS SC and BFS SC). About 15 minutes afterparticipants' first responses to BFS and BAS, the interviewer drove conversation to SC-related subjects (e.g., "Do you know people who are your same age? In your opinion, how are they physically and aesthetically?"). Then, the interviewer gave the following instructions to participants: "I would like you think about people of your same age. You can think about people you know, or you see at TV shows or magazines." A minute later, participants completed the BAS and BFS.

Body satisfaction and TC theory (BAS TC and BFS TC). About 15 minutes after social comparison's responses, the interviewer 
drove conversation to TC-related subjects (e.g., "Which physical activities did you do when you were younger? How old were you at that moment?"). Then, participants completed BAS and BFS once more.

\section{Body satisfaction and SS theory (BAS SS).}

About 15 minutes after temporal comparison's responses, the interviewer drove conversation to the subject of participants' aesthetic body care (e.g., "Do you utilize creams or cosmetics to your body or face? How often do you shave yourself?"). A few minutes later, the interviewer gave the following instructions to participants: "I would like you imagine yourself, in front of a mirror, when you are sprucing up for a special occasion." One minute after receiving these instructions, participants completed for the last time the BAS.

In the present study, participants did not receive any theory-related stimuli from the researcher before completing BAS and BFS for the first time. Therefore, these measures were considered as the "baseline" measures. As proceeded by Ryff, ${ }^{11}$ participants were asked some open-ended questions before receiving theory-related instructions, and then answering body satisfaction scales. This procedure was assumed to facilitate the shift to thinking in terms of comparisons with same-age peers (SC), intrapersonal comparisons (TC), and cognitive schema constructions (SS).

\section{Statistical Analysis}

Overall, we used non-parametric tests. Men did not differ from women regarding all BAS and BFS measures. Therefore, statistical analyses were performed for the whole sample. Friedman test was used to verify if participants' responses regarding theoryrelated stimuli differed for BAS and BFS, separately. Spearman rank correlations were used to verify how BFS and BAS baseline scores were correlated with the other BFS and BAS measures. Partial correlations were run for BFS and BAS assessments, controlling for age, level of physical function decline and/ or number of chronic diseases. Correlations between BFS or BAS (baseline) and other variables were also examined.

\section{RESULTS}

Participants' median age was 81.5 years; just seven people had completed 12 years of education (none of them had a university diploma). Most of participants $(\mathrm{n}=15)$ also presented some difficulty in performing $\geq 1$ ADL. Participants' median score for the physical function decline was 20 (mean value $=18 \pm 4.9$ ), while it was 4.5 for the ADL scale (mean value $4.7 \pm 3.5$ ). They had a median of 3.5 diseases (from 2 to 8 , mean $=4.1 \pm 1.7$. All participants had at least 2 diseases), and most of them $(n=10)$ regularly suffered of osteo-articulatory chronic pain. Thirteen persons rated their general health as "poor" or "fair", and five reported they had a "good" health. Their BMI varied from $20.3 \mathrm{~kg} /$ $\mathrm{m}^{2}$ to $45.3 \mathrm{~kg} / \mathrm{m}^{2}$, with a median value of 25.9 $\mathrm{kg} / \mathrm{m}^{2}\left(\right.$ mean $\left.=27 \mathrm{~kg} / \mathrm{m}^{2} \pm 6.4\right)$.

We did not find differences between genders regarding all measures of BAS (baseline, $\mathrm{p}=.21$; SC, $\mathrm{p}=.18$; TC, $\mathrm{p}=.13$; SS, $\mathrm{p}=.10)$ and BFS (baseline, $\mathrm{p}=.36$; $\mathrm{SC}, \mathrm{p}=.06$; $\mathrm{TC}, \mathrm{p}=.06$ ). Therefore, statistical analyses were performed for men and women together. Friedman test indicated that BFS baseline (median $=11$, mean value $=10.8 \pm 2.7)$, BFS SC (median $=11.7$, mean value $=11.5 \pm 3.8$ ), and BFS TC (median $=11.7$, mean value $=12 \pm 3.9)$ did not differ one another $(\mathrm{p}=.226)$. Regarding BAS scores, BAS baseline (median $=10$, mean value $=8.8 \pm 2.5$ ), BAS SC (median $=9$, mean value $=9.1 \pm 2.7$ ), BAS TC $($ median $=9.5$, mean value $=8.3 \pm 3.4$ ), and BAS SS (median $=9$, mean value $=8.7 \pm$ 3.4) also did not differ each other $(p=.217)$.

Table 1 shows correlations between baseline scores and theory-based responses of BFS and BAS, respectively. It also shows correlations between BAS and BFS baseline scores and other variables. BFS baseline-BFS TC relationship had a higher coefficient of correlation than BFS baseline-BFS SC; when controlled for age $(\mathrm{n}=$ $15, \mathrm{r}=0.828, \mathrm{p}<.001$; and $\mathrm{r}=0.767, \mathrm{p}<.001$, 
respectively), for age and number of diseases ( $\mathrm{n}=14, \mathrm{r}=0.871, \mathrm{p}<.001$; and $\mathrm{r}=0.810, \mathrm{p}$ $<.001$, respectively), and for age and physical function decline $(\mathrm{n}=14, \mathrm{r}=0.779, \mathrm{p}<.001$, and $\mathrm{r}=0.752, \mathrm{p}=.001)$ this result seemed to remain unchanged. Regarding correlations among BAS scores, BAS baseline-BAS TC relationship presented the highest coefficient of correlation, followed by BAS baseline-BAS SC, and BAS baseline-BAS SS; these results seemed to remain unchanged when correlations were controlled for age $(\mathrm{n}=15, \mathrm{r}=0.934, \mathrm{p}<.001 ; \mathrm{r}=0.907, \mathrm{p}$ $<.001$; and $\mathrm{r}=0.845, \mathrm{p}<.001$, respectively), for age and number of diseases $(n=14, r=0.908$, $\mathrm{p}<.001 ; \mathrm{r}=0.867, \mathrm{p}<.001 ;$ and $\mathrm{r}=0.770, \mathrm{p}<$ $.001)$, and for age and physical function decline ( $\mathrm{n}=14, \mathrm{r}=0.922, \mathrm{p}<.001 ; \mathrm{r}=0.890, \mathrm{p}<.001$; and $\mathrm{r}=0.815, \mathrm{p}<.001)$. The other significant correlations occurred between BAS baseline and BMI, and BAS baseline and number of diseases.

Table 1 - Baseline BAS and BFS correlations with other variables (Marseille, 2010)

\begin{tabular}{|c|c|c|c|c|}
\hline \multirow[t]{3}{*}{ Variables } & \multicolumn{2}{|c|}{ Baseline BAS } & \multicolumn{2}{|c|}{ Baseline BFS } \\
\hline & \multicolumn{2}{|c|}{ Coefficient } & \multicolumn{2}{|c|}{ Coefficient } \\
\hline & (r) & $p$. & $(r)$ & $p$ \\
\hline BAS SC & 0.887 & $<0.001$ & - & - \\
\hline BAS TC & 0.929 & $<0.001$ & - & - \\
\hline BAS SS & 0.840 & $<0.001$ & - & - \\
\hline BFS SC & - & - & 0.722 & 0.001 \\
\hline BFS TC & - & - & 0.849 & $<0.001$ \\
\hline Age & 0.113 & 0.66 & 0.411 & 0.09 \\
\hline BMI & -0.604 & 0.008 & -0.332 & 0.18 \\
\hline Functional limitation's score & -0.434 & 0.07 & -0.139 & 0.58 \\
\hline Number of diseases & -0.502 & 0.03 & -0.122 & 0.63 \\
\hline
\end{tabular}

Note. - BAS SC = body appearance scale social comparison; BAS TC = body appearance scale temporal comparison; BAS SS = body appearance scale self-schema; BFS SC = body functioning scale social comparison; BFS TC = body functioning scale temporal comparison; BMI = body mass index.

\section{DISCUSSION}

This work showed that BAS TC and BFS TC were strongly correlated to BAS baseline and BFS baseline, respectively; the coefficients of these correlations were higher than they were for the other BAS (BAS SC-BAS baseline, and BAS SS-BAS baseline) and BFS (BFS SC-BFS baseline) correlations. These results seemed to remain unchanged even when correlations were controlled for age and number of diseases, or age and physical function decline. BAS measurements as well as BFS ones did not differ one another. Taken together, these results suggest that TC theory may be a useful framework for understanding elderly' perceptions of their body functioning and appearance, at least among functionally limited older persons.

Although some researchers ${ }^{20}$ have indicated that temporal comparisons regarding physical health aspects in older adults tend to be unfavorable, we did not find any difference across BAS and BFS measurements. This might have occurred because our sample is composed of vulnerable elderly (presenting co-morbidity and difficulties in carrying out daily activities), who had low levels of body satisfaction. It is possible 
that, due to the high vulnerability of participants, a "floor effect" have occurred for all body satisfaction measurements, mainly regarding body functioning dimension. Indeed, their mean values of BFS and BAS (baseline measures) were $10.8 \pm 2.7$ and $8.8 \pm 2.5$, respectively; whereas in another research, which used the same BFS and BAS measures ${ }^{21}$ in a sample composed of functionally limited elderly, participants mean values were $15 \pm 3.6$ and $9.4 \pm 2.6$, respectively.

The relationship between BFS baseline and BFS TC was probably influenced by the level of physical function decline, because the coefficient of correlation decreased when the relationship was controlled for physical function decline (from $r=0.828$ to $r=0.779)$. It is plausible to think that more vulnerable persons have unfavorable temporal comparisons because they probably have experienced high physical declines. It was not the case for the BFS SC-BFS baseline relationship; participants may have thought that their same-age peers have experienced equivalent physical declines than they did (the coefficient of correlation decreased just a little when this relationship was controlled for physical function decline). Relationships between BAS baseline and the other measurements of BAS (SC, TC, and SS) were probably not influenced by age and physical function declines. However, the coefficient of correlation of the relationship between BAS SS and BAS baseline decreased after controlling for number of diseases (from $r=0.845$ to $r=0.770$ ); chronic diseases have already been suggested as important aspects in determining body satisfaction. ${ }^{16}$ Why the number of diseases was involved specifically in this BAS relationship is not clear, and deserves further investigations.

The correlations found between BAS TC and BAS baseline, and BFS TC and BFS baseline were stronger than correlations between the other BAS (SC, and SS) and BFS (SC) measures, even when adjusted for control variables. This suggests that TC may be a useful theoretical framework for the field of body satisfaction. Although some studies have already shown the importance of
TC in explaining older adults' mood state and functional status, ${ }^{22}$ and psychological wellbeing, ${ }^{11}$ this theory has never been used in the body satisfaction field. The present study is, as far as we know, the first one that used TC theory in the field of body satisfaction in the elderly; therefore, it offers preliminary indications on TC usefulness for this research area. Although this study adds new information for the debate of elderly' perceptions of their bodies, its small sample size and inclusion criteria (functionally limited individuals) preclude results' generalization. Regarding study methodology, we cannot affirm that there was no "memory effect" among consecutive responses of BAS and BFS. However, time intervals between theory-related stimuli, as well as interviews' content (interviews approached other subjects than body satisfaction), probably contributed to reduce the risk of a "memory effect". Another important point of the study methodology is that participants were blinded regarding the use of different theoretical frameworks in the understanding of body satisfaction; in this way, they did not know that BAS and BFS would be administered at several moments during the interview, and then they were not previously "stimulated" to always give the same answers across the sequential BAS and BFS measurements.

\section{CONCLUSIONS}

Temporal comparisons are important to determine elderly' adjustment to aging. ${ }^{11,23}$ However, this assumption cannot be directly assumed in the field of body satisfaction. Further research should be encouraged to confirm if TC theory is a valid framework for explaining elderly' body satisfaction. Studies with large sample size composed of both functionally limited and nonfunctionally limited older adults can shed light on the usefulness of TC theory in this area. Studies that disentangle how the different theories (TC, SC, SS) interact to determine elderly' body satisfaction will also add relevant information to this field. 


\section{REFERENCES}

1. Donaghued N. Body satisfaction, sexual selfschemas and subjective well-being in women. Body Image 2009; 6:37-42.

2. Festinger L. A theory of social comparison processes. Human Relations 1954; 7(2):117-140.

3. Buunk AP, Gibbons FX. Social comparison: the end of a theory and the emergence of a field. Organizational Behavior and Human Decision Processes 2007; 102:3-21, doi:10.1016/j. obhdp.2006.09.007

4. Dittmar H. Vulnerability factors and processes linking sociocultural pressures and body dissatisfaction. Journal of Social and Clinical Psychology 2005; 24:1081-87.

5. Franzoi SL, Klaiber JR. Body use and reference group impact: with whom do we compare our bodies? Sex Roles 2007; 56:205-214. DOI: 10.1007/ s11199-006-9162-4.

6. Krayer A, Ingledew DK, Iphofen R. Social comparison and body image in adolescence: a grounded theory approach. Health Educ Res 2008; 23(5):892-903.

7. Miller E, Halberstadt J. Media consumption, body image, and thin ideals in New Zealand men and women. New Zealand Journal of Psychology 2005; 34:189-195.

8. Markus H. Self-schemata and processing information about the self. Journal of Personality and Social Psychology 1977; 35:63-78.

9. Altabe M, Thompson KJ. Body image: a cognitive self-schema construct? Cognitive Therapy and Research 1996; 20(2):171-193.

10. Van Den Berg P, Thompson JK. Self-schema and social comparison explanations of body dissatisfaction: A laboratory investigation. Body Image 2007; 4:29-38.

11. Ryff CD. Possible selves in adulthood and old age: a tale of shifting horizons. Psychology and Aging 1991; 6(2):286-295.

12. Albert S. Temporal comparison theory. Psychol Rev 1977; 84:485-503.

13. Brown R, Middendorf J. The underestimated role of temporal comparison: a test of the life-span model. Journal of Social Psychology 1996; 136(3):325-331.
14. Tiggemann M. Body image across the adult life span: stability and change. Body Image 2004; 1:29-41.

15. Stuck AE, Walthert JM, Nikolaus T, Bula CJ, Hohmann C, Beck JC. Risk factors for functional status decline in community-living elderly people: a systematic literature review. Social Science and Medicine 1999; 48, 445-469.

16. Pruzinsky T. Enhancing quality of life in medical populations: a vision for body image assessment and rehabilitation as standards of care. Body Image 2004; 1:71-81.

17. Reboussin BA, Rejeski WJ, Martin KA, Callahan K, Dunn AL, King AC et al. Correlates of satisfaction with body function and body appearance in middleand older aged adults: the Activity Counseling Trial (ACT). Psychology and Health 2000; 15:239-254.

18. Barreto, P.S., Ferrandez, A-M., Guihard-Costa, A-M. Predictors of body satisfaction: differences between older men and women's perceptions of their body functioning and appearance. Journal of Aging and Health 2011; 23(3) : 505-528. DOI: 10.1177/0898264310386370.

19. Barreto PS, Ferrandez A-M. Activités instrumentales physiques de la vie quotidienne chez les personnes âgées : validation d'une échelle. In : ChapuisLucciani N, Guihard-Costa A-M, Boëtsch G. L'anthropologie du vivant : objets et méthodes. 2010, 83-87. Retrived on January 3rd 2011, at the following electronic site: http://www.evolhum.cnrs. $\mathrm{fr} /$ methodes-anthropobio/desoutobarreto.pdf

20. Suls J, Marco CA, Tobin S. The role of temporal comparison, social comparison, and direct appraisal in the elderly's self-evaluations of health. Journal of Applied Social Psychology 1991; 21:1125-44.

21. Barreto PS. Physical activity level among functionally limited and robust older adults: is body satisfaction predictive of physical activity level? Revista Portuguesa de Ciências do Desporto 2010; 10(1 Suppl): 69-70.

22. King KB, Clark PC, Friedman MM. Social comparisons and temporal comparisons after coronary artery surgery. Heart and Lung 1999; 28:316-335

23. Rickabaugh CA, Tomlinson-Keasey C. Social and temporal comparisons in adjustment to aging. Basic and Applied Social Psychology 1997; 79(3):307-328. 